\title{
Potassium metabolism and diuretics administration in liver cirrhosis
}

\author{
P. VESIN \\ M.D. \\ Department of Internal Medicine, Villeneuve-St-Georges, France
}

\begin{abstract}
Summary
The author first reviews, on the basis of personal and literature data, the main changes in three major parameters of potassium metabolism: serum potassium; daily urinary output of potassium; exchangeable potassium (Ke) at the three stages of the course of liver cirrhosis. The action of K-sparing diuretics (spironolactone, triamterene, amiloride) on these parameters is analysed. Although the introduction of these diuretics in our therapeutic armamentarium has resulted in a major advance, i.e. the quasi-total elimination of iatrogenic hypokalaemia and hypokalaemia-induced portacaval encephalopathy in the cirrhotic, the limits of their action on $K$ metabolism are underlined: they may moderately enhance urinary $K$ output; following cessation of their administration, a 'rebound' in urinary $K$ output may be noted. Finally, Ke may still continue to decrease during their administration, indicating an aggravation of the underlying disease. It was also found that a rise in serum $K$ and/or Ke during amiloride administration did not prevent the elevation of plasma renin activity usually induced by volume and/or $\mathrm{Na}$ depletion.
\end{abstract}

THE retention of salt and water in the cirrhotic patient requires the administration of diuretics. Following the initial publication by Read et al. (1959) of studies of cirrhotic patients treated with chlorothiazide, it became apparent that severe accidentsespecially portacaval encephalopathy related to diuretic-induced hypokalaemia-were quite common. An increased production of ammonium by the kidney was shown to follow diuretic-induced (or spontaneous) hypokalemia (Gabuzda and Hall, 1966). Therefore, a better comprehension of $\mathrm{K}$ metabolism in patients with liver cirrhosis is of major therapeutic interest. We shall first review the anomalies of $\mathrm{K}$ metabolism at the three stages of liver cirrhosis which we have identified (Vesin, 1972a). Three parameters are considered: serum potassium (Ks); the daily urinary output of $\mathrm{K}(\mathrm{Ku})$; total body potassium, as grossly assessed by the determination of

Reprint requests to: Dr P. Vesin, 31, rue de Moscou, 75008 Paris, France. exchangeable potassium $(\mathrm{Ke})$. The main changes are indicated on Table 1.

(1) At the initial stage of liver cirrhosis (Stage I), salt and water retention is mild and transient, overt oedema and ascites are absent and there is no rationale for the use of diuretics. Serum $\mathrm{K}$ is normal, so is the daily urinary output of $\mathrm{K}$. Ke also is usually normal as shown by the studies of Casey, Summerskill and Orvis (1965) and of Traverso et al. (1966).

TABLE 1. Main $\mathbf{K}$ parameters at the three stages of liver cirrhosis. (I) Oedema-free, normal renal function; (II) ascites-oedema, moderate renal failure; (III) ascites-oedema, severe renal failure

\begin{tabular}{|c|c|c|c|}
\hline & I & II & III \\
\hline Ks & N1 & & \\
\hline $\mathbf{K u}$ & $\mathrm{N} 1$ & & \\
\hline $\mathrm{Ke}$ & $\mathrm{N} 1$ & & \\
\hline
\end{tabular}

A significant reduction of $\mathrm{Ke}$ was noted only in a few cases by these authors. In patients made oedemafree by the administration of diuretics, Nagant de Deuxchaisnes et al. (1961) noted a decrease in Ke; however, these patients had reached the second stage of liver cirrhosis.

Stage II is characterized by the existence of a marked retention of salt and water, ascites and oedema, mainly as the result of aldosterone hypersecretion ('hyperaldosteronic' oedema). Ks is either normal or at the lower limit of normality (Traverso et al., 1966). In some cases, especially those complicated by diarrhoea, a major cause of $\mathrm{K}$ depletion, marked hypokalaemia $(<3 \mathrm{mEq} / \mathrm{l})$ may be noted. The daily urinary $\mathbf{K}$ output can be somewhat increased, or normal, or even a little decreased, as compared to normal values. The sometimes reduced 
figures may be due to a factor which will be of great importance at Stage III, i.e. the increased resorption of $\mathrm{Na}$ in sections of the renal tubule located proximal to the distal tubule ion transport area. A reduced $\mathrm{K}$ intake may also be a cause. $\mathrm{Ke}$ is usually markedly reduced as found by Casey et al. (1965), Nagant de Deuxchaisnes et al. (1961), Traverso et al. (1966), Vesin et al. (1972). Only seven of the thirty patients investigated by our group (Traverso et al., 1966; Vesin et al., 1972) had a normal $\mathrm{Ke}$, in the remaining twenty-three, $\mathrm{Ke}$ was markedly decreased, sometimes below $50 \%$ of the theoretically normal value. Casey et al. (1965), Traverso et al. (1966) and Vesin et al. (1972) all stressed the prognostic value of a strong reduction in $\mathrm{Ke}$, especially when developing at repeated determinations. The mechanism of $\mathrm{Ke}$ decrease is complex. Vesin (1972a) analysed the responsible factors, namely: reduced $\mathrm{K}$ intake due to lack of appetite; destruction of the cellular mass; diarrhoea; diuretics; alkalosis; although hypersecretion of aldosterone is common in these patients, $\mathrm{Ku}$, as mentioned above, is not markedly increased and may even be lowered as noted by Vesin and Traverso (1975). Thus, urinary K loss-indirectly resulting from aldosterone hypersecretion (see below) - does not appear to be a major factor of the severe $\mathrm{Ke}$ reduction seen in these patients.

At Stage III, on account of the renal hypoperfusion syndrome developing at that stage and responsible for terminal functional renal failure (Vesin and Traverso, 1975), the bulk of water and $\mathrm{Na}(\mathrm{Cl})$ is resorbed proximal to the distal convoluted tubule. Therefore, the distal resorption of $\mathrm{Na}$ under the action of aldosterone is reduced, which limits the electrical gradient, resulting in a diminished excretion of $\mathrm{K}$ into the lumen of the distal tubule (Malnic, de Mello Aires and Giebisch, 1971). Metabolic acidosis commonly observed at that stage (Vesin, 1972a) may also play a minor part in this reduction. Ks sharply increases and may reach values above 5.5-6 mEq/l. Ku falls to figures sometimes below $20 \mathrm{mEq} / 24 \mathrm{hr}$ (Vesin, 1972b). Ke is also markedly decreased, entailing a poor prognosis (Casey et al., 1965; Nagant de Deuxchaisnes et al., 1961 ; Traverso et al., 1966).

(2) The management of diuretic therapy to control and eliminate the accumulation of salt and water in the cirrhotic patient should be based on the advances made in our knowledge of $\mathrm{K}$ metabolism.

To-day, a major hazard of the diuretic therapy of patients with liver cirrhosis-hypokalaemia-induced portacaval encephalopathy-has been eliminated. Since the discovery of the so-called K-retaining or (more appropriately) K-sparing diuretics, which include spironolactone, triamterene and amiloride, it is no longer necessary to resort to diuretics such as chlorothiazide and derivates, ethacrinic acid, furose- mide, which markedly enhance urinary $\mathrm{K}$ excretion, often leading to hypokalaemia. The administration of $\mathrm{K}$-sparing diuretics is always accompanied by a moderate rise in serum potassium values. We have treated hundreds of patients with spironolactone, triamterene or amiloride, without ever observing the development of hypokalaemia. We do recommend the administration of these diuretics alone, as their association with diuretics such as furosemide, etha- कै crinic acid, etc., still entails a risk of hypokalaemia (Yamada \& Reynolds, 1970). We also use glucocorticoids (especially prednisone) as diuretic agents; in our experience, this has never led to hypokalaemia, or $\mathrm{K}$ depletion. However, one must exert caution when assessing the so-called $\mathrm{K}$-sparing or retaining effects of spironolactone, triamterene and amiloride.

Firstly, they may enhance the urinary excretion of $\mathrm{K}$ as compared to pre-treatment baseline values. In the course of a study, in twenty-six patients, of the action of amiloride upon the daily urinary output of $\mathrm{K}$, Vesin, Roberti and Viguie (1969) noted that the excretion was reduced by $10-20 \mathrm{mEq}$ in four cases only, did not change $( \pm 10 \mathrm{mEq})$ in twelve, and increased by $10-40 \mathrm{mEq}$ in twelve; Surveyor and Saunders (1968) made similar observations; they noted that in some patients the urinary excretion of $\mathrm{K}$ was reduced initially, but increased later. A increase of $\mathrm{Ku}$ in patients given a $\mathrm{K}$-sparing diuree may seem paradoxical. It may be due to the well established increase in aldosterone secretion observed in these patients during diuretic administration (Vesin, 1972a). In the patients given amiloride, the excretion of $K$ seemed to be directly related to $\overrightarrow{\vec{B}}$ the urinary output of $\mathrm{Na}$, an indirect finding in $\frac{\mathrm{O}}{3}$ favour of the role of an increased aldosterone secre- $\bar{T}$ tion (Vesin et al., 1969). The increased aldosterone secretion enhances distal tubular $\mathrm{Na}$ resorption and the transtubular electric gradient is increased, result- 3 ing in a greater excretion of $K$ into the tubular lumen. The usual increase in Ks may also be a factor of urinary $\mathrm{K}$ excretion.

Secondly, the 'rebound' noted by Surveyor and Saunders (1968) during the administration of amilor-을 ide may sometimes be observed only after cessation of diuretic therapy, as exemplified on Fig. 1, showing the $\mathrm{Ku}$ changes seen in a patient given spironolac- $N$ tone; the 'rebound' may be of great magnitude, e.g. $\$$ up to $400 \mathrm{mEq} /$ day in one of the patients treated $N$ with spironolactone (Vesin et al., 1972); the action $N$ of aldosterone hypersecretion may also represent aq reasonable explanation for the increased $\mathrm{Ku}$.

Thirdly, the eventual changes in $\mathrm{Ke}$ were also investigated in patients with liver cirrhosis treated by a K-sparing diuretic. Amiloride $(30 \mathrm{mg} /$ day) was 70 given to ten patients for a period of 10 days. Ke was determined before, and on the last day of the $\stackrel{D}{\square}$ administration of amiloride and the following $\stackrel{\mathbb{Q}}{\varrho}$ 


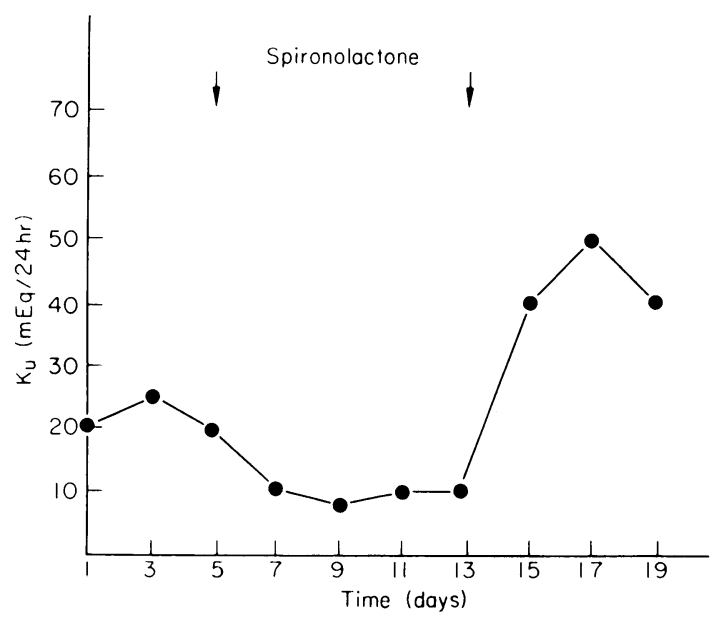

FIG. 1. Urinary $\mathrm{K}$ output changes in a cirrhotic patient given spironolactone.

changes were noted: Ke decreased by $30 \%$ in two patients, by $>10 \%$ in two, did not vary in three, and increased significantly in three (Vesin et al., 1972). Similar observations were made by Lévy et al. (1970) in cirrhotics treated with spironolactone.

How can one explain the maintenance or even the decrease of $\mathrm{Ke}$ instead of the increase one would expect with K-sparing diuretics? The two following mechanisms are proposed:

(1) In some patients, the increase in $\mathrm{Ku}$ suffices to account for a moderately negative $\mathrm{K}$ balance, inasmuch as $\mathrm{K}$ intake is more or less reduced.

(2) Extra-urinary sources of $\mathrm{K}$ loss may also exist, with special reference to diarrhoea.

Furthermore, the K-sparing diuretics do not suppress a major anomaly of $\mathrm{K}$ metabolism in these patients: the inability of the cells to retain or bind $\mathrm{K}$ as shown by Nagant de Deuxchaisnes et al. (1961) in cirrhotic patients given a large $\mathrm{K}$ load. The inability of the cells to bind $\mathrm{K}$ may also account for the 'rebound' in urinary $\mathrm{K}$ excretion reported above, following cessation of $\mathrm{K}$-sparing diuretic administration. As the loss of large amounts of $\mathrm{K}$ in the urine does not result in a dramatic decrease in serum $\mathrm{K}$, this cation is likely to have been retained in a loose form in the cells under the action of the K-sparing diuretics. The cessation of this action with the termination of diuretic administration is accompanied by release of the retained $\mathrm{K}$ which is eliminated in the urine. For this reason, supplementation of cirrhotic patients with $\mathrm{K}$ chloride during the administration of K-sparing diuretics, advocated by Lévy et al. (1970), can only result, in the opinion of Vesin et al. (1972), in a transient Ke increase at the best, and may even prove dangerous if severe functional renal failure develops during diuretic therapy. It is only in those patients in whom there is a marked improvement of the general condition and liver function that a significant and lasting Ke increase can be expected. It is also worth mentioning that in four patients treated with prednisone with loss of oedema and general improvement, a mean $\mathrm{Ke}$ increase of $12 \%$ was noted by Traverso et al. (1966).

Finally, the effect of an increased $\mathrm{Ke}$ and/or $\mathrm{Ks}$ following amiloride administration on plasma renin activity (PRA) was investigated. It has been reported repeatedly that a potassium load results in a decrease in PRA. Nevertheless, it was observed, in this investigation, that the retention of $\mathrm{K}$ and/or the increase in Ks did not prevent the increase in PRA usually observed after volume and/or $\mathrm{Na}$ depletion (Vesin et al., 1972). These findings have been confirmed by Dluhy, Cain and Williams (1974) in normal subjects in whom the administration of diuretics and the ensuing plasma and/or $\mathrm{Na}$ depletion resulted in an increased PRA, despite the concomitant administration of a $\mathrm{K}$ load.

\section{References}

Casey, T.H., Summerskill, W.H.J. \& Orvis, A.L. (1965) Body and serum potassium in liver disease. 1. Relationship to hepatic function and associated factors. Gastroenterology, 48, 198.

Dluhy, R.G., Cain, J.P. \& Williams, G.H. (1974) The influence of dietary potassium on the renin and aldosterone response to diuretic-induced volume depletion. Journal of Laboratory and Clinical Medicine, 83, 249.

GabUzDA, G.J. \& Hall, P.W. (1966) Relation of potassium depletion to renal ammonium metabolism and hepatic coma. Medicine, 45, 481 .

Lévy, V.G., Lassale, B., del Curso, A. \& Caroli, J. (1970) Effet de l'aldactone sur le stock potassique chez les cirrhotiques ascitiques. Annales de Médecine Interne. 121, 183.

Malnic, G., De Mello Aires \& Giebisch, G. (1971) Potassium transport across renal distal tubule during acid-base disturbances. American Journal of Physiology, 221, 1192.

Nagant de Deuxchaisnes, C., Busset, R., Collet, R.A. \& $\mathrm{MACH}_{\mathrm{AC}}$ R.S. (1961) Exchangeable potassium in wasting, amyotrophy, heart-disease and cirrhosis of the liver. Lancet, i, 681 .

Read, A.E., Laidlan, J., Haslam, R.M. \& Sherlock, S. (1959) Neuropsychiatric complications following chlorothiazide therapy in patients with hepatic cirrhosis: possible relation to hypokalaemia. Clinical Science, 18, 409.

Surveyor, I. \& SAunders, R.A. (1968) Amiloride and plasma potassium. Lancet, ii, 516.

Traverso, H.D., Raynaud, Cl., Blanchon, P., Roberti, A., Vesin, P., Viguie, R. \& Kellershohn, C. (1966) Etude des clearances de l'inuline et du PAH, du débit cardiaque, du $\mathrm{Na}$ et du K échangeables et des liquides extra-cellulaires au cours de l'évolution de la cirrhose du foie. Revilue internationale d'Hépatologie, 16, 1377.

VESIN, P. (1972a) Water, electrolyte and acid-base disorders in liver disease. In: Clinical Disorders of Fluid and Electrolyte Metabolisin (Ed. by M. H. Maxwell and C. R. Kleeman), p. 873. McGraw Hill, New York.

Vesin, P. (1972b) Potassium supplements and diuretics. Lancet, ii, 1262.

Vesin, P., Meyer, Ph., Troupel, S., El Guedry, H., Sfarti, M., Renault, H. \& Viguie, R. (1972) Exchangeable potassium and plasma renin in cirrhotic patients receiving 
a potassium-retaining diuretic (amiloride). Vth International Congress of Nephrology.

Vesin, P., Roberti, A. \& Viguie, R. (1969) Actions de l'amiloride (MK870) sur le métabolisme hydro-électrolytique du cirrhotique ascitique. Schweizerische Medizinische Wochenschrift, 99, 21.
Vesin, P. \& Traverso, H. (1975) Functional renal failure $\zeta$

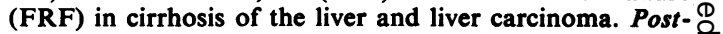
graduate Medical Journal, 51, 489.

YAMADA, S. \& REYNoldS, T.B. (1970) Amiloride (MK870) A new antikaluretic diuretic. Gastroenterology, 59, 833. 